\title{
Sven Simon
}

\section{Liberalisierung von Dienstleistungen der Daseinsvorsorge im WTO- und EU-Recht}

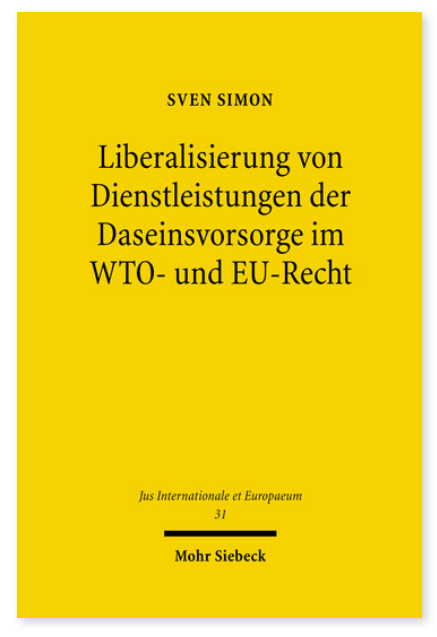

2009. XVII, 416 Seiten. JusIntEu 31

ISBN 978-3-16-151170-7

DOI 10.1628/978-3-16-151170-7

eBook PDF $89,00 €$

ISBN 978-3-16-150000-8

fadengeheftete Broschur 89,00€
Die Liberalisierung von Dienstleistungen der Daseinsvorsorge ist Gegenstand einer kontroversen politischen Debatte. Sven Simon analysiert die Liberalisierungsstruktur der beiden maßgeblichen Verträge und geht der Frage nach, ob Dienstleistungen der Daseinsvorsorge im WTO- oder EU-Recht einem Liberalisierungszwang unterworfen sind. Er setzt sich mit der komplexen Struktur des GATS auseinander, erörtert den Anwendungsbereich sowie die Rechtfertigungsmöglichkeit binnenmarktrechtlicher Beschränkungen des EG-Vertrages und bewertet die Auswirkungen des Protokolls zur Daseinsvorsorge im Vertrag von Lissabon. Das Untersuchungsergebnis stellt er in einen breiteren sozioökonomischen und politischen Kontext. Dabei skizziert er auch, wie der europäische und der internationale Rechtsrahmen zur gemeinwohlorientierten Gestaltung der Globalisierung beitragen können.

Sven Simon Geboren 1978; Studium der Rechtswissenschaft an der Justus-Liebig-Universität Gießen und der University of Warwick (Großbritannien); 2008-2010 Rechtsreferendar am Landgericht Gießen mit Stationen in Frankfurt, Berlin, Tel Aviv (Israel) und New York (USA); 2009 Promotion; 2010-15 Akademischer Rat an der Universität Gießen; 2015 Habilitation; Verleihung der Lehrbefugnis für die Fächer Öffentliches Recht, Europarecht, Völkerrecht und Internationales Wirtschaftsrecht.
Jetzt bestellen:

https://mohrsiebeck.com/buch/liberalisierung-von-dienstleistungen-der-daseinsvorsorge-im-wto-und-eu-recht-

9783161511707?no_cache=1

order@mohrsiebeck.com

Telefon: +49 (0)7071-923-17

Telefax: $+49(0) 7071-51104$ 